Research paper

\title{
Prefrontal activity during experimental ostracism and daily psychache in suicide attempters
}

\author{
Emilie Olié ${ }^{\mathrm{a}, \mathrm{b}, *}$, Mathilde Husky ${ }^{\mathrm{e}}$, Emmanuelle Le Bars ${ }^{\mathrm{c}, \mathrm{d}}$, Jeremy Deverdun ${ }^{\mathrm{d}}$, \\ Nicolas Menjot de Champfleur ${ }^{\mathrm{c}, \mathrm{d}}$, Adrian Alacreu Crespo ${ }^{\mathrm{a}, \mathrm{b}}$, Joel Swendsen ${ }^{\mathrm{f}}$, \\ Philippe Courtet ${ }^{\mathrm{a}, \mathrm{b}}$

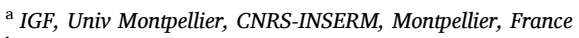 \\ ${ }^{\mathrm{b}}$ Department of Emergency Psychiatry and Acute Care, Lapeyronie Hospital, CHU Montpellier, Montpellier, France \\ ${ }^{\mathrm{c}}$ Department of Neuroradiology, Academic Hospital of Montpellier \& U1051, Institut of Neurosciences of Montpellier, Montpellier, France \\ ${ }^{\mathrm{d}}$ I2FH, Institut d'Imagerie Fonctionnelle Humaine, Montpellier University Hospital, Gui de Chauliac Hospital, Montpellier, France \\ ${ }^{\mathrm{e}}$ Laboratoire de psychologie, EA4139, UNiversité de Bordeaux, Bordeaux, France \\ ${ }^{\mathrm{f}}$ EPHE PSL Research University, University of Bordeaux CNRS 5287, Institut Universitaire de France
}

\section{A R T I C L E I N F O}

\section{Keywords:}

Social exclusion

Ecological momentary assessment

Psychological pain

Suicide

fMRI

\begin{abstract}
A B S T R A C T
Background: Suicidal behaviors can result from a complex interaction between social stressors and individual vulnerability. Evidence suggests a specific neural processing of social cues in suicide attempters without knowledge of how it relates to real-world experiences.

Objective: To investigate the association between brain activity during experimental social exclusion (measured by functional MRI) and psychological pain in daily life (assessed by Ecological Momentary Assessment) in patients with a lifetime history of suicide attempt.

Methods: Thirty-three euthymic females with a history of a major depressive episode were recruited: 13 suicide attempters and 20 affective controls (no history of suicide attempt). Functional MRI scans were acquired while participants played the Cyberball game, a validated social exclusion paradigm. After fMRI, participants completed EMA for a one-week period. Five times per day, they were asked to rate their psychological pain, hopelessness and the negativity of daily events. EMA indices (psychological pain, hopelessness and their interaction with negative events) were correlated with cerebral activations using a ROI approach (orbitofrontal, dorsal and ventrolateral prefrontal cortices, anterior cingulate cortex and insula) in each group.

Results: We found a negative correlation between daily ratings of psychological pain and orbitofrontal activation for exclusion versus inclusion during the Cyberball game in suicide attempters but not in affective controls. We did not find correlations between cerebral activation and daily hopelessness ratings.

Limitations: Small sample size

Conclusion: Scanner-based orbitofrontal activity during social exclusion relates to psychological pain in daily life which participates in suicide risk among vulnerable individuals.
\end{abstract}

\section{Introduction}

Psychological pain, defined as an acute state of intense "feelings of guilt, anguish, fear, panic, angst, loneliness and helplessness" (Schneidman, 1996), has been associated with suicidal ideation and suicidal behavior (Ducasse et al., 2017). It has been shown to be predictive of suicide attempts over a one-year period in depressed patients
(Alacreu-Crespo et al., 2020), and emerges from the frustration of essential psychological needs. Four of these needs (belonging, self-esteem, control and meaningful existence) are threatened by social exclusion or rejection (Williams et al., 2000). Importantly, almost $80 \%$ of suicide victims have experienced at least one or more adverse life events within the last year (particularly, in the immediate months preceding suicide; Heikkinen et al., 1994). Interpersonal conflicts are

\footnotetext{
* Corresponding author at: Department of Emergency Psychiatry \& Post Acute Care, Academic Hospital of Montpellier 371 avenue Doyen Gaston Giraud 34295 Montpellier cedex 5 France.

E-mail address: e-olie@chu-montpellier.fr (E. Olié).
} 
events that constitute the greatest risk for suicidal acts independently of mental disorders (Foster, 2011) and, in suicide attempters, being alone and experiencing negative family-related events increase suicidal ideation (Husky et al., 2017). Longitudinal studies also suggest that social exclusion participates in suicidal ideation. For instance, chronic relational victimization (i.e. bullying) increases the likelihood of later suicidal ideation in adolescents (Brunstein Klomek et al., 2019).

Accumulating evidence suggests that suicide is not associated only with a propensity to be involved in negative social situations but also with limited ability to manage them. For example, suicide attempters are unable to de-emphasize the importance of a perceived problem or source of stress (Horesh et al., 1996). According to the Three Step Theory of suicide (Klonsky and May, 2015), an ideation-to-action theory of suicide, the combination of pain (usually psychological) and hopelessness is the first step to suicidal ideation. Individuals who exhibit maladaptive neural processing of social rejection may be at elevated risk for suicidal ideation or behavior when confronted with negative social events because such experiences are more likely to elicit negative emotions, including psychological pain. The investigation of the neural basis of social rejection and associated psychological pain is therefore crucial for understanding suicide vulnerability in order to identify potential therapeutic targets. Recent research has combined fMRI with the Cyberball game, a virtual ball tossing task that simulates social exclusion, in euthymic patients with or without a lifetime history of suicide attempts (Olie et al., 2017). During this task, the participant plays a virtual ball-tossing game with two other supposedly real participants. However, the participant is not informed that he or she will progressively be excluded from the game by the two other participants who will increasingly play together. Compared to patients without any history of suicide attempt and healthy controls, suicide attempters demonstrated decreased contrast in the left insula and supramarginal gyrus during the exclusion vs. inclusion condition (Olie et al., 2017). Focusing on the insula and dorsal anterior cingulate cortex, Caceda et al. (2019) failed to show any differences for cerebral activation in acutely suicidal vs. non-suicidal patients and controls during the exclusion vs. inclusion condition. Neural responses in the cingulate cortex were positively correlated with physical but not psychological pain during social exclusion. Neuroimaging evidence for structural, functional, and molecular alterations in association with suicidal behavior converges in regions of prefrontal cortex and insula (Schmaal et al., 2020) which are also involved in the processing of social exclusion (Eisenberger et al., 2003).

In light of increasing interest in the neural underpinnings of social and emotional processes involved in psychopathology, it is important to assess whether neural reactivity to specific social or emotional experiences assessed through neuroimaging has meaningful correlations with real-world experiences. Ecological Momentary Assessment (EMA) is a reliable method for capturing thoughts, feelings, and behaviors as close in time to their occurrence as possible and within the natural contexts of daily life (Shiffman et al., 2008), including in persons with history of suicidal behavior (Husky et al., 2017). Interestingly, EMA has been shown to capture suicidal ideation that is undetectable when using retrospective reports and therefore helps to further understand at-risk subgroups (Gratch et al., 2020). In line with this, Eisenberger and colleagues (2007) reported that healthy controls who showed greater activity in the dorsal anterior cingulate cortex, amygdala, and periaqueductal gray during the Cyberball game reported greater daily momentary social distress. Another study showed EMA-measured negative social experiences moderated the association between suicidal ideation and right insular activation during social rejection (using the Chatroom Interact Task) in anxious adolescents (Oppenheimer et al., 2020). The aim of the present investigation is to expand this line of research in order to better understand neural processes participating in suicide vulnerability. We investigated the association between prefrontal reactivity to social exclusion using the Cyberball game with emotional responses to daily life stressors assessed by EMA in patients with or without a history of suicide attempts.

\section{Materials and methods}

\subsection{Participants}

This study is part of a larger investigation of mood disorders and suicide risk using fMRI (Olie et al., 2017) conducted in the Department of Emergency Psychiatry and Post-Acute Care at the Montpellier Academic hospital, France. Participants were first screened for inclusion criteria and then evaluated by a psychiatrist. All participants were right-handed (as assessed by the Edinburgh scale; Oldfield, 1971) and Caucasian females. Only patients and not healthy controls were proposed EMA. This subsample was divided into 2 groups according to the lifetime history of suicidal behavior (suicidal behavior was defined as any act carried out with some intent to die). Thirty-three euthymic female participants with a past history of major depressive episode were recruited among outpatients of the Department of Emergency Psychiatry and Post-Acute Care at the Montpellier Academic hospital, France. Participants were first screened for inclusion criteria and then evaluated by a psychiatrist. Only females were included in this study due to the heightened sensitivity to daily stressors observed among women and because most previous studies using the Cyberball game were conducted with women.

Diagnoses were made according to DSM-IV criteria using the MiniInternational Neuropsychiatric Interview, version 5.0.0. All participants were required to be euthymic at the time of scanning, as indicated by a Hamilton Depression Rating Scale score $<7$ and a Young Mania Rating Scale score $<7$. Other exclusion criteria were a lifetime history of severe head trauma, CNS disorder, schizophrenia, and a history of alcohol or drug abuse or dependence within the past 12 months. The local Ethics Committee (CPP Sud Méditerranée IV, CHU Montpellier) approved the study protocol. All experimental methods were carried out in accordance with the ethical guidelines determined by the National Ministry of Health, Labor and Welfare and the Declaration of Helsinki. All participants provided written informed consent before study enrolment.

We administered the French version of the National Adult Reading Test (NART) (Mackinnon et al., 1999) to provide an estimate of premorbid verbal IQ. We measured history of childhood maltreatment with the Childhood Trauma Questionnaire (CTQ; Scher et al., 2004). All psychotropic treatments (name, daily dose) during the last $24 \mathrm{~h}$ before MRI were recorded. We calculated a medication load for each patient according to Sackeim et al. (2001).

\subsection{Functional MRI task: cyberball game}

Functional Magnetic Resonance Imaging (fMRI) scans were acquired while participants played the Cyberball game, a virtual ball-tossing game (Williams et al., 2000). The Cyberball game is a validated paradigm to study social exclusion and it has been widely used in fMRI studies. Participants were instructed that they would play with two other players, also in fMRI scanners. In reality, participants were playing with a pre-established computer program and were provided an explanation to ensure that they believed the other players were real. The Cyberball game comprises three successive conditions. In the first condition (Implicit Social Exclusion, ISE), the participant watched the other "players" play the Cyberball game. Participants were told that because of technical difficulties the link to the other two scanners could not yet be made and thus, at first, they would only watch but not play with the other two players. This story was intended to allow participants to view a scene visually identical to the exclusion condition (Explicit Social Exclusion, ESE) without participants experiencing exclusion by the other participants. In the second condition (inclusion, INC), participants played with the other two players and received the ball as many times as virtual players. In the final condition (ESE), participants were 
progressively excluded by the two other players who did not throw the ball to the participant anymore. Each trial consisted of 60 throws by condition, i.e. 180 throws in total for the whole session. The fictive players waited 0.5-3.0 seconds before making a throw to heighten the sense that the participant was actually playing with other individuals. ESE included 8 throws to the participant during an initial transition phase toward total exclusion.

Following completion of the Cyberball task, participants completed the Need-Threat Scale (NTS; Williams et al., 2000) to measure social distress associated with being excluded during the game. The NTS assesses 20 subjectively-experienced consequences of being excluded during the game, including ratings of self-esteem ("I felt liked"), belongingness ("I felt rejected"), meaningfulness ("I felt invisible"), and control ("I felt powerful"), on a scale ranging from $1=$ "not at all" to $5=$ "very much". Items were reverse-coded when appropriate and averaged to create a composite score.

\subsection{Image acquisition}

Imaging acquisition was performed in the Neuroradiology Department - I2FH (Academic Hospital of Montpellier) - using a 1.5T wholebody MRI system (MAGNETON AVANTO, Siemens, Erlangen, Germany) equipped with a standard 12-channel receive-only head coil. Sixty volumes of BOLD echo planar images (EPI) were obtained during the Cyberball Game. Gradient-Echo EPI image characteristics were as follows: $\mathrm{TR}=2 \mathrm{~s}, \mathrm{TE}=40 \mathrm{~ms}, \mathrm{FOV}=220 \mathrm{~mm}, 25$ axial slices $(5 \mathrm{~mm}$ slice thickness), slice gap $=0.5 \mathrm{~mm}$, voxel size $=3.43 \times 3.43 \times 5 \mathrm{~mm}$, flip angle $90^{\circ}$. The slices were covering a region extending from the vertex to lower parts of the cerebellum. A 3D magnetization-prepared, rapid acquisition gradient echo (MP-RAGE) sequence was also obtained for each participant with the following parameters: TR $=2100$ $\mathrm{ms}, \mathrm{TE}=4.1 \mathrm{~ms}$, Inversion time $=1100 \mathrm{~ms}, 15^{\circ}$ flip angle, $\mathrm{PAT}=2$, aligned with the corpus callosum, voxel-size $0.98 \times 0.98 \times 1 \mathrm{~mm}, 160$ transversal slices.

\subsection{Ecological momentary assessment (EMA)}

After fMRI, participants were trained in how to use the mobile assessment device (a Tungsten E2 palm computer) for the EMA phase of the study. The 15-min training session on computerized EMA included the operation of the device as well as verifying comprehension of each question and response choice as displayed in the electronic interview. After completion of training, each participant was given an EMA device to carry with them for 7 consecutive days. Each device was programmed to administer five electronic interviews per day. For each individual, the timing of the interviews occurred within a sampling window ranging from 8:00 a.m. and 10:00 p.m. However, to avoid a concentration of electronic interviews within several minutes of each other, this time window was divided into five time periods of 3 to $4 \mathrm{~h}$. One electronic interview was then administered within each time period, with a minimum spacing of $1 \mathrm{~h}$ between any two electronic interviews. For any given individual, the interviews occurred each day at the same time. Furthermore, sampling windows were adjusted to accommodate each participant's typical sleep and wake schedules so as to not modify usual daily life activities. The EMA program permitted responses to be provided only within a 20-min period following the interview signal, and all data entries were time-stamped. Among the EMA questions, participants were asked to rate on Likert scales their degree of psychological pain and hopelessness in the moment, ranging from 1 (no distress) to 7 (extreme distress), as well as the negativity of the most significant daily event experienced since the previous EMA assessment from 1 (not at all negative) to 7 (extremely negative). All participants were contacted by phone by a member of the research team on the second day of the study to answer any questions and resolve any technical issue, and again on the fifth day to remind them to charge the device. Following the sevenday assessment period, participants returned the device to the research staff. The interactions of psychological pain and hopelessness with daily event negativity were calculated, reflecting the degree of psychological pain or hopelessness experienced in relation with preceding negative daily event. These calculations were accomplished by multiplying the score of psychological pain or hopelessness by the degree of event negativity for each individual using their unique EMA data, resulting in individual interaction coefficients for each participant.

\section{5. fMRI data analysis}

Data were analyzed using SPM12 (Wellcome Department of Imaging Neuroscience, London, UK) implemented in Matlab R2015 (Mathworks, Inc., Natick, MA) using a block-design model. The 5 first volumes of each fMRI run were discarded due to the time of launch of the Cyber ball task synchronized with fMRI acquisition. The following 55 volumes were retained for functional analysis for each condition (ISE, INC and ESE). In total 165 volumes were analyzed. EG-EPI data were re-oriented to the anterior commissure, slice-time corrected, realigned to the first volume, co-registered, normalized to $\mathrm{T} 1$ template (provided by the Montreal Neurological Institute, MNI), and smoothed with an 8-mm FWHM Gaussian filter.

Contrast images were estimated for both ESE vs. INC and ISE vs. INC conditions for every participant using a first-level general linear model. Realignment parameters were added in the regressor to remove head movement effects. For all fMRI analyzes, we performed an a priori ROI approach. The ROIs were anatomically defined with Anatomical Automatic Labeling (AAL), using masks provided by the Wake Forest University PickAtlas software (http://fmri.wfubmc.edu) (Fig. 1). Based on the literature (Caceda et al., 2019; Ding et al., 2015; Olie et al., 2015, 2017), we defined 5 ROIs relevant for social rejection and suicidal vulnerability: 1) orbitofrontal cortex (OFC) as orbital parts of the inferior frontal gyrus, middle frontal gyrus and medial frontal gyrus (including medial and lateral parts) (corresponding to Brodmann areas (BA 11/47); 2) ventrolateral prefrontal cortex (VLPFC) as the opercular part of the inferior frontal gyrus (BA 44/45); 3) dorsal prefrontal cortex (DPFC) as the middle frontal gyrus (BA 8/9/46); 4) anterior cingulate cortex (ACC) (BA 24/32); and 5) insula (Fig. 1). Average beta values in each ROI were then extracted for ESE vs. INC and ISE vs. INC contrasts.

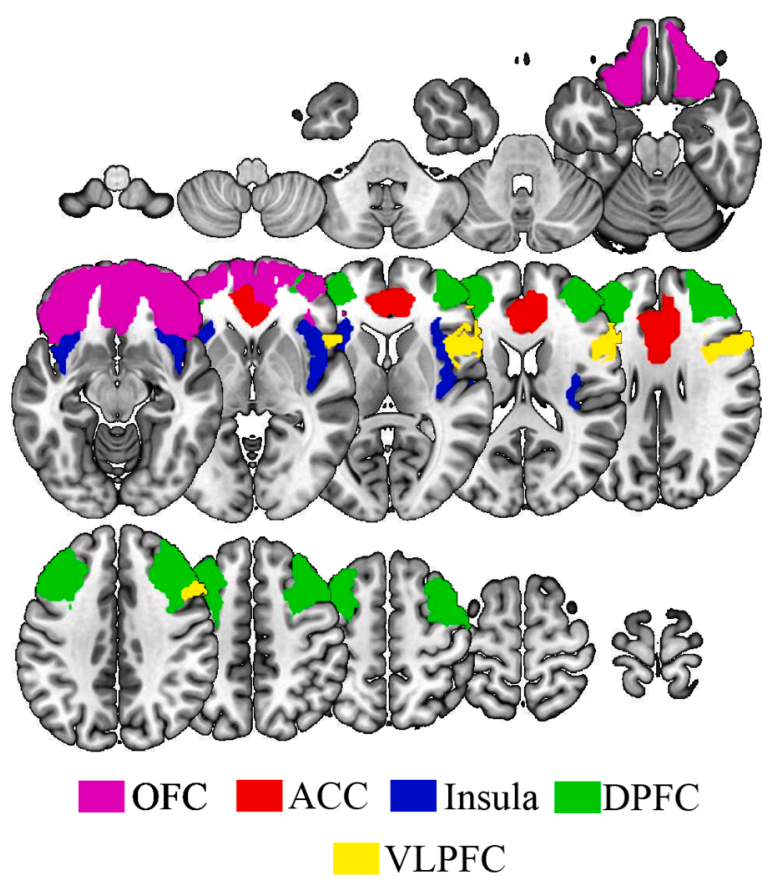

Fig. 1. Regions of Interest. 


\subsection{Statistical analyses}

Clinical and behavioral analyses were conducted using SPSS Statistics 21 (SPSS, Inc., Chicago). Group differences for the clinical and behavioral data were tested using t-tests for quantitative variables and chi-square tests for qualitative variables. SA and AC groups were split and Spearman correlations were performed between brain activation (for each condition) with EMA measures, using a significance level of $\mathrm{p}$ FDR corrected $<0.05$ (to account for multiple comparisons). The significant correlations were compared between groups using Fisher tests.

\section{Results}

\subsection{Sociodemographic and clinical data}

There were no between-group differences for sociodemographic data, characteristics of mood disorder, medication load as well as assessments of emotional stress (Table 1). Suicide attempters had a mean age of 28.08 ( $S D=7.73$ ) years at the first suicide attempt and a mean number of $2(\mathrm{SD}=1)$ suicidal acts. Participants responded to an average of $81 \%$ ( $S D=0.39$ ) of the EMA programmed signals over the study period. A total of 928 daily events were experienced by the sample of which the majority (55\%) concerned social relationships or social interactions with family, romantic partners or friends.

\subsection{Correlation between EMA measures and experimental social exclusion}

There was no significant correlation between the Need Threat Scale and absolute ratings of psychological pain or hopelessness, or between the Need Threat Scale and the interaction of these two variables with event negativity. In SA but not AC, daily psychological pain was negatively correlated with the activation of OFC $(r=-0.77 ; p=0.04)$ (Fig. 2), and a trend correlation was observed with activation of DPFC ( $\mathrm{r}$

Table 1

Description of the sample.

\begin{tabular}{|c|c|c|c|c|}
\hline $\begin{array}{l}\text { Sociodemographic and clinical } \\
\text { information }\end{array}$ & $\begin{array}{l}\mathrm{AC}(\mathrm{N}= \\
20) \\
\text { Mean } \\
(\mathrm{SD})\end{array}$ & $\begin{array}{l}\text { SA }(N= \\
13) \\
\text { Mean } \\
\text { (SD) }\end{array}$ & $\begin{array}{l}\text { Statistics } \\
\text { Student }\end{array}$ & $\begin{array}{l}\mathrm{p} \\
\text { value }\end{array}$ \\
\hline Age & $\begin{array}{l}34.92 \\
(8.9)\end{array}$ & $\begin{array}{l}41.45 \\
(10.8)\end{array}$ & 1.88 & 0.07 \\
\hline Level of education (years) & $\begin{array}{l}14.35 \\
(1.8)\end{array}$ & $\begin{array}{l}13.92 \\
(1.8)\end{array}$ & -0.65 & 0.5 \\
\hline $\mathrm{N}$ of past depressive episodes & $3.2(3.2)$ & $3.6(3.2)$ & 0.39 & 0.7 \\
\hline Age at mood disorder onset & $\begin{array}{l}27.08 \\
(7.7)\end{array}$ & $\begin{array}{l}22.55 \\
(6.3)\end{array}$ & 1.72 & 0.09 \\
\hline Medication load & $2.25(1.9)$ & $2.54(1.6)$ & 0.44 & 0.6 \\
\hline CTQ, total score & $\begin{array}{l}45.35 \\
(18.11)\end{array}$ & $\begin{array}{l}46.62 \\
(12.57)\end{array}$ & 0.22 & 0.82 \\
\hline Need Threat Scale, total score & $\begin{array}{l}65.95 \\
(13.6)\end{array}$ & $\begin{array}{l}66.69 \\
(13.4)\end{array}$ & 0.15 & 0.87 \\
\hline \multicolumn{5}{|l|}{ EMA measures } \\
\hline Psychological pain & $1.7(1.27)$ & $\begin{array}{l}1.91 \\
(1.04)\end{array}$ & 0.49 & 0.62 \\
\hline $\begin{array}{l}\text { Interaction of psychological pain } \\
\text { and negative events }\end{array}$ & $\begin{array}{l}8.02 \\
(9.02)\end{array}$ & $\begin{array}{l}7.56 \\
(4.26)\end{array}$ & -0.16 & 0.87 \\
\hline Hopelessness & $\begin{array}{l}4.82 \\
(1.01)\end{array}$ & $\begin{array}{l}4.45 \\
(1.21)\end{array}$ & 0.27 & 0.66 \\
\hline $\begin{array}{l}\text { Interaction of hopelessness and } \\
\text { negative events }\end{array}$ & $\begin{array}{l}19.43 \\
(7.39)\end{array}$ & $\begin{array}{l}17.04 \\
(5.73)\end{array}$ & 0.86 & 0,33 \\
\hline \multicolumn{5}{|l|}{ Current psychopathology } \\
\hline Generalized Anxiety Disorder & 4 & 2 & & \\
\hline Post Traumatic Stress Disorder & 0 & 1 & & \\
\hline Agoraphobia & 1 & 1 & & \\
\hline Panic disorder & 1 & 2 & & \\
\hline Social phobia & 1 & 0 & & \\
\hline
\end{tabular}

CTQ = Childhood Trauma Questionnaire; EMA = Ecological Momentary Assessment.
$=-0.67 ; \mathrm{p}=0.07)$ and ACC $(\mathrm{r}=-0.66 ; \mathrm{p}=0.07)$ during experimental explicit social exclusion vs. inclusion (ESE vs INC). There was also a trend for a negative correlation between psychological pain following daily negative events and OFC activation $(r=-0.66 ; p=0.07)$ during the exclusion vs inclusion phase of the Cyberball Game. A comparison between SA and AC correlations (i.e., psychological pain and OFC activation) was significant $\left(\mathrm{z}=-3.43, \mathrm{p}<10^{-3}\right)$. There were no correlations between hopelessness in an absolute sense or in interaction with negative events and cerebral activations in either AC or SA. (Table 2). For ISE vs INC, there were no significant correlations between brain activations and EMA measures in both groups (Table 3).

\section{Discussion}

The present study found that neural activity assessed within the fMRI scanner has a meaningful relationship with real-world social and emotional experience in suicide attempters. The results showed an association between activation of OFC during experimental explicit social exclusion and the emergence of psychological pain following daily negative events in persons with a past history of suicide attempts, whereas there was no correlation between subjective experimental social distress and daily ratings of negative emotions. There was a trend for a correlation between OFC activation during the Cyberball game and the interaction between psychological pain and the preceding negative daily event. Unlike Eisenberger et al. (2007), we did not find an association between emotional experience in daily life and activation of ACC during the Cyberball Game. This discrepancy may be explained by different processing of social distress between suicide attempters and healthy controls, both at the behavioral and neural levels (Caceda et al., 2019; Olie et al., 2017). Interestingly, we did not find any correlations between daily life measures and cerebral activations for ISE vs. INC. Social distress is related to ESE and self-regulation of this distress occurs in response to ESE (Eisenberger et al., 2003). These findings therefore suggest that feeling excluded (ESE) is more associated with psychological pain in suicide attempters than exclusion by itself (ISE).

To our knowledge, only Caceda et al. (2019) have investigated associations between neural bases of the Cyberball Game and psychological pain in this population, and found a positive association between psychological pain and activation of ACC during social inclusion but not exclusion. The discrepancy with our results may be explained by their inclusion of severely suicidal (vs. euthymic) patients as well as by their retrospective assessment of psychological pain by visual analog scales rather than EMA measures. However, our results are in the line with other functional imaging studies that highlight a relationship between prefrontal regions and psychological pain in suicide attempters (Jollant et al., 2016; Meerwijk et al., 2013; Reisch et al.; van Heeringen et al., 2010). Interestingly, in suicide attempters vs. controls, OFC activation was correlated with psychological pain during a cognitive inhibition task (Richard-Devantoy et al., 2016). Moreover, Caceda et al. (2014) reported a decrease in psychological pain and suicidal ideation concomitantly with the improvement of choice impulsivity in suicide attempters. In depressed patients, decision-making influences the emergence of suicidal ideation when psychological pain is high (Alacreu-Crespo et al., 2019). Interestingly, OFC dysfunction underlies impaired decision making that characterizes euthymic patients having a history of suicide attempts (Jollant et al., 2010; Olie et al., 2015). Although speculative, the present results may suggest that individuals experiencing more psychological pain in daily life would be less prone to activate OFC in social contexts which would facilitate disadvantageous decision-making and impulsive choices, both contributing to suicidal behavior.

To our knowledge, this study is the first to combine fMRI and EMA to investigate the emergence of psychological pain in a clinical sample. The prospective design and use of daily assessments help characterize the temporal direction between daily life events and the emergence of psychological pain while also reducing the likelihood of recall bias. With 


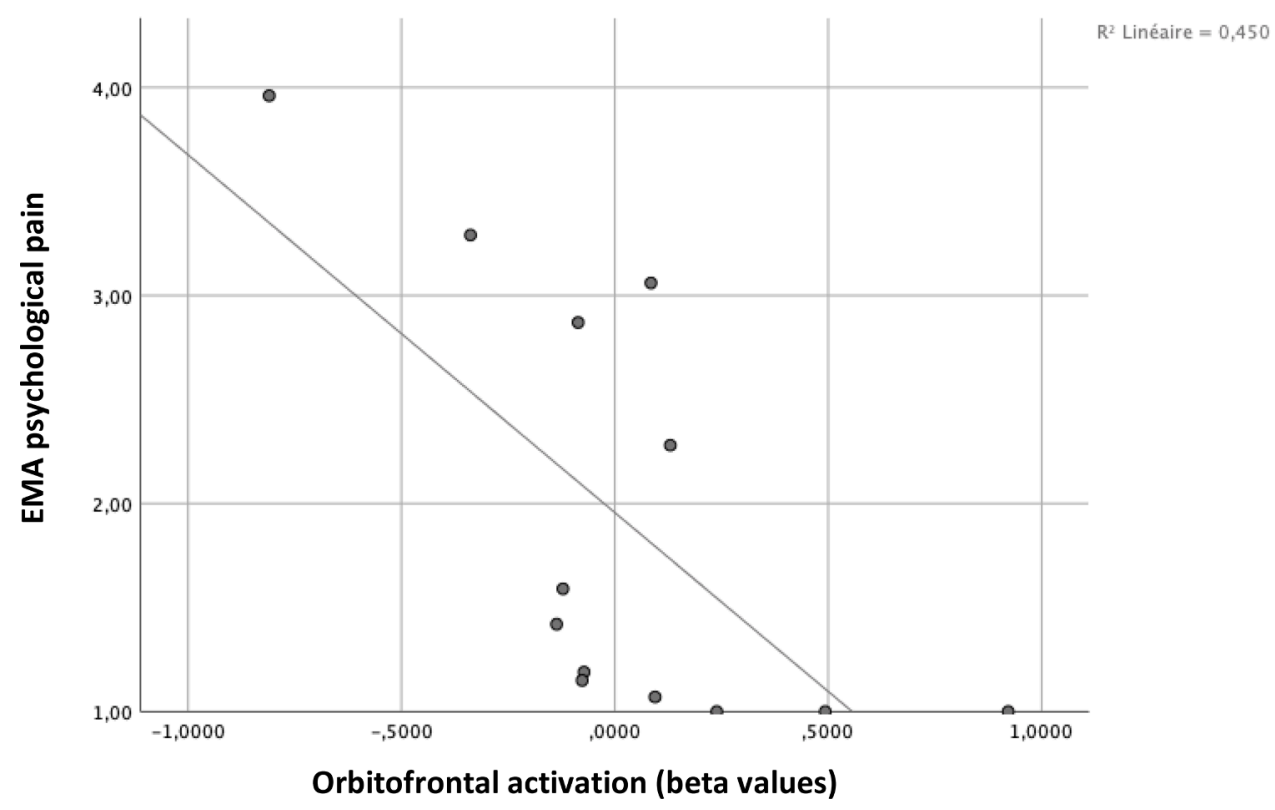

Fig. 2. Correlation between daily life psychological pain and orbitofrontal cortex activation during Cyberball game.

Table 2

Correlations between daily life emotional measures (EMA) and ROI activations for explicit social exclusion (ESE) vs. inclusion (INC) of Cyberball Game for suicide attempters and affective controls.

\begin{tabular}{|c|c|c|c|c|c|}
\hline & OFC & DPFC & VLPFC & ACC & Insula \\
\hline \multicolumn{6}{|c|}{ Affective Controls $(N=20)$} \\
\hline $\begin{array}{l}\text { Psychological } \\
\text { pain }\end{array}$ & $\begin{array}{l}r=0.34 \\
(p=0.37)\end{array}$ & $\begin{array}{l}r=0.50 \\
(p=0.25)\end{array}$ & $\begin{array}{l}r=0.28 \\
(p=0.92)\end{array}$ & $\begin{array}{l}r=0.33 \\
(p=0.37)\end{array}$ & $\begin{array}{l}r=0.31 \\
(p=0.42)\end{array}$ \\
\hline $\begin{array}{l}\text { Psychological } \\
\text { pain by } \\
\text { negative } \\
\text { event }\end{array}$ & $\begin{array}{l}r=0.38 \\
(p=0.32)\end{array}$ & $\begin{array}{l}r=0.51 \\
(p=0.25)\end{array}$ & $\begin{array}{l}r=0.02 \\
(p=0.93)\end{array}$ & $\begin{array}{l}r=0.38 \\
(p=0.50)\end{array}$ & $\begin{array}{l}\mathrm{r}=0.43 \\
(\mathrm{p}=0.28)\end{array}$ \\
\hline Hopelessness & $\begin{array}{l}r=-0.27 \\
(p=0.46)\end{array}$ & $\begin{array}{l}r=-0.15 \\
(p=0.77)\end{array}$ & $\begin{array}{l}r=-0.18 \\
(p=0.69)\end{array}$ & $\begin{array}{l}r=-0.24 \\
(p=0.32)\end{array}$ & $\begin{array}{l}r=-0.44 \\
(p=0.28)\end{array}$ \\
\hline $\begin{array}{l}\text { Hopelessness } \\
\text { by negative } \\
\text { event }\end{array}$ & $\begin{array}{l}r=-0.11 \\
(p=0.86)\end{array}$ & $\begin{array}{l}r=-0.06 \\
(p=0.92)\end{array}$ & $\begin{array}{l}r=0.02 \\
(p=0.93)\end{array}$ & $\begin{array}{l}r=-0.28 \\
(p=0.46)\end{array}$ & $\begin{array}{l}r=-0.06 \\
(p=0.92)\end{array}$ \\
\hline \multicolumn{6}{|c|}{ Suicide Attempters $(N=13)$} \\
\hline $\begin{array}{l}\text { Psychological } \\
\text { pain }\end{array}$ & $\begin{array}{l}r=-0.77 \\
(p=0.04)\end{array}$ & $\begin{array}{l}r=-0.67 \\
(p=0.07)\end{array}$ & $\begin{array}{l}r=-0.15 \\
(p=0.77)\end{array}$ & $\begin{array}{l}r=-0.66 \\
(p=0.07)\end{array}$ & $\begin{array}{l}r=-0.44 \\
(p=0.34)\end{array}$ \\
\hline $\begin{array}{l}\text { Psychological } \\
\text { pain by } \\
\text { negative } \\
\text { event }\end{array}$ & $\begin{array}{l}r=-0.66 \\
(p=0.07)\end{array}$ & $\begin{array}{l}r=-0.48 \\
(p=0.1)\end{array}$ & $\begin{array}{l}r=-0.37 \\
(p=0.43)\end{array}$ & $\begin{array}{l}r=-0.53 \\
(p=0.20)\end{array}$ & $\begin{array}{l}r=-0.21 \\
(p=0.76)\end{array}$ \\
\hline Hopelessness & $\begin{array}{l}r=-0.43 \\
(p=0.34)\end{array}$ & $\begin{array}{l}r=-0.35 \\
(p=0.43)\end{array}$ & $\begin{array}{l}r=-0.03 \\
(p=0.92)\end{array}$ & $\begin{array}{l}r=-0.36 \\
(p=0.43)\end{array}$ & $\begin{array}{l}r=-0.88 \\
(p=0.81)\end{array}$ \\
\hline $\begin{array}{l}\text { Hopelessness } \\
\text { by negative } \\
\text { event }\end{array}$ & $\begin{array}{l}r= \\
-0.159 \\
(p=0.76)\end{array}$ & $\begin{array}{l}r=-0.19 \\
(p=0.76)\end{array}$ & $\begin{array}{l}r=-0.10 \\
(p=0.81)\end{array}$ & $\begin{array}{l}r=-0.13 \\
(p=0.80)\end{array}$ & $\begin{array}{l}r=0.22 \\
(p=0.76)\end{array}$ \\
\hline
\end{tabular}

ACC $=$ anterior cingulate cortex DPFC $=$ dorsal prefrontal cortex; OFC = orbitofrontal cortex; $r=$ Spearman coefficient; $\mathrm{VLPFC}=$ ventrolateral prefrontal cortex.

the widespread and increasing use of smartphones, EMA can be used in routine clinical practice to acquire data that was previously difficult or impossible to collect. Nevertheless, the study has specific limitations that should be considered in interpreting its findings. First, the small sample may have limited the detection of significant results due lack of power. Second, only women were included, and results may not generalize to men. Third, the definition of psychological pain remains a source of debate. However, our results for psychological pain were different from those for hopelessness, strengthening the hypothesis that psychological pain is a specific construct relevant to understanding the process of suicidal ideation and behavior. When compared to
Table 3

Correlations between daily life emotional measures (EMA) and ROI activations for implicit social exclusion (ISE) vs. inclusion (INC) of Cyberball Game for suicide attempters and affective controls.

\begin{tabular}{|c|c|c|c|c|c|}
\hline & OFC & DPFC & VLPFC & ACC & Insula \\
\hline \multicolumn{6}{|c|}{ Affective Controls $(N=20)$} \\
\hline $\begin{array}{l}\text { Psychological } \\
\text { pain }\end{array}$ & $\begin{array}{l}r=0.097 \\
(p=0.81)\end{array}$ & $\begin{array}{l}r= \\
-0.099 \\
(p=0.81)\end{array}$ & $\begin{array}{l}r=0.25 \\
(p=0.46)\end{array}$ & $\begin{array}{l}r=0.10 \\
(p=0.81)\end{array}$ & $\begin{array}{l}r=0.26 \\
(p=0.46)\end{array}$ \\
\hline $\begin{array}{l}\text { Psychological } \\
\text { pain by } \\
\text { negative } \\
\text { event }\end{array}$ & $\begin{array}{l}r=0.07 \\
(p=0.81)\end{array}$ & $\begin{array}{l}r=0.08 \\
(\mathrm{p}=0.81)\end{array}$ & $\begin{array}{l}r=0.32 \\
(p=0.46)\end{array}$ & $\begin{array}{l}r=0.15 \\
(p=0.69)\end{array}$ & $\begin{array}{l}r=0.25 \\
(p=0.46)\end{array}$ \\
\hline Hopelessness & $\begin{array}{l}r=0.08 \\
(p=0.81)\end{array}$ & $\begin{array}{l}r=-0.11 \\
(p=0.81)\end{array}$ & $\begin{array}{l}r=0.17 \\
(p=0.63)\end{array}$ & $\begin{array}{l}r=0.05 \\
(p=0.87)\end{array}$ & $\begin{array}{l}r=-0.03 \\
(p=0.91)\end{array}$ \\
\hline $\begin{array}{l}\text { Hopelessness } \\
\text { by negative } \\
\text { event }\end{array}$ & $\begin{array}{l}r=0.17 \\
(p=0.63)\end{array}$ & $\begin{array}{l}r=0.19 \\
(p=0.61)\end{array}$ & $\begin{array}{l}\mathrm{r}=0.27 \\
(\mathrm{p}=0.46)\end{array}$ & $\begin{array}{l}r=0.27 \\
(p=0.46)\end{array}$ & $\begin{array}{l}\mathrm{r}=0.03 \\
(\mathrm{p}=0.91)\end{array}$ \\
\hline \multicolumn{6}{|c|}{ Suicide Attempters $(N=13)$} \\
\hline $\begin{array}{l}\text { Psychological } \\
\text { pain }\end{array}$ & $\begin{array}{l}r=-0.49 \\
(p=0.46)\end{array}$ & $\begin{array}{l}r=-0.36 \\
(p=0.46)\end{array}$ & $\begin{array}{l}r=-0.38 \\
(p=0.46)\end{array}$ & $\begin{array}{l}r=-0.56 \\
(p=0.46)\end{array}$ & $\begin{array}{l}r=-0.39 \\
(p=0.46)\end{array}$ \\
\hline $\begin{array}{l}\text { Psychological } \\
\text { pain by } \\
\text { negative } \\
\text { event }\end{array}$ & $\begin{array}{l}r=-0.42 \\
(p=0.46)\end{array}$ & $\begin{array}{l}r=-0.41 \\
(p=0.46)\end{array}$ & $\begin{array}{l}r=-0.46 \\
(p=0.46)\end{array}$ & $\begin{array}{l}r=-0 ; 52 \\
(p=0.46)\end{array}$ & $\begin{array}{l}r=-0.41 \\
(p=0.46)\end{array}$ \\
\hline Hopelessness & $\begin{array}{l}r=-0.35 \\
(p=0.46)\end{array}$ & $\begin{array}{l}r=-0.47 \\
(p=0.46)\end{array}$ & $\begin{array}{l}r=-0.43 \\
(p=0.46)\end{array}$ & $\begin{array}{l}r=-0.48 \\
(p=- \\
0.46)\end{array}$ & $\begin{array}{l}r=-0.37 \\
(p=0.46)\end{array}$ \\
\hline $\begin{array}{l}\text { Hopelessness } \\
\text { by negative } \\
\text { event }\end{array}$ & $\begin{array}{l}r=-0.26 \\
(p=0.60)\end{array}$ & $\begin{array}{l}r=-0.37 \\
(p=0.46)\end{array}$ & $\begin{array}{l}r=-0.32 \\
(p=0.46)\end{array}$ & $\begin{array}{l}r=-0.33 \\
(p=0.46)\end{array}$ & $\begin{array}{l}r=-0.33 \\
(p=0.46)\end{array}$ \\
\hline
\end{tabular}

$\mathrm{ACC}=$ anterior cingulate cortex; $\mathrm{DPFC}=$ dorsal prefrontal cortex; $\mathrm{OFC}=$ orbitofrontal cortex; $r$ = Spearman coefficient; $\mathrm{VLPFC}=$ ventrolateral prefrontal cortex.

hopelessness and depression, psychological pain was found to be a stronger predictor of suicidality (Troister et al., 2015). An additional limitation to consider is that we used an ROI approach. Although neuroanatomy of suicidal behaviors likely encompasses many brain regions and networks (Jollant et al., 2011), focusing on specific regions-of-interest (ROI) may be more successful than whole brain analyzes in confirming previously-identified brain regions. This approach reduces the potential over-correction for multiple tests at the expense of the investigation of new regions (Poldrack, 2007). 
In summary, this study utilized a novel technique to assess whether neural reactivity to a single experimental episode of social rejection in an fMRI scanner is related to real-world experience. Examining the relationships between neural responses gained through fMRI scanner and real-world experiences may provide important information regarding neurocognitive processes that underlie negative affect and suicidal vulnerability. Studies that investigate the impact of interventions focusing on executive functions and social cognition are particularly needed in order to improve suicide prevention.

\section{Author statement}

Emilie Olié contributed substantially to analyses and interpretation of the data; she drafted the manuscript and gave final approval of the version to be published. Emmanuelle LeBars, Nicolas Menjot de Champfleur and Jeremy Deverdun contributed substantially to acquisition and interpretation of imaging data and revised the manuscript critically for important intellectual content and gave final approval of the manuscript. Mathilde Husky and Adrian Alacreu contributed to the data processing and analysis, and gave final approval of the manuscript. Joel Swendsen and Philippe Courtet contributed substantially to the conception and design of the study, the interpretation of data, revision of the manuscript for important intellectual content and gave final approval of the manuscript.

The authors declare having no conflicts of interest related to this manuscript.

Funding source : Pr. Philippe Courtet received a grant from the National Agency for Research ANR MNPS 2009 "VASCO". Mathilde Husky, Adrian Alacreu, Joel Swendsen, Emilie Olié Emmanuelle LeBars, Nicolas Menjot de Champfleur and Jeremy Deverdun have not received grants.

\section{Declaration of Competing Interest}

None.

\section{Acknowledgements}

None.

\section{Supplementary material}

Supplementary material associated with this article can be found, in the online version, at doi:10.1016/j.jad.2021.01.087.

\section{References}

Alacreu-Crespo, A., Cazals, A., Courtet, P., Olie, E., 2020. Brief assessment of psychological pain to predict suicidal events at one year in depressed patients. Psychother. Psychosom. 1-4.

Alacreu-Crespo, A., Olie, E., Seneque, M., Beziat, S., Guillaume, S., Costa, R., Courtet, P., 2019. Decision-making skills moderate the relationship between psychological and physical pain with suicidal behavior in depressed patients. Psychother. Psychosom. 88, 190-191.

Brunstein Klomek, A., Barzilay, S., Apter, A., Carli, V., Hoven, C.W., Sarchiapone, M., Hadlaczky, G., Balazs, J., Kereszteny, A., Brunner, R., Kaess, M., Bobes, J., Saiz, P.A., Cosman, D., Haring, C., Banzer, R., McMahon, E., Keeley, H., Kahn, J.P., Postuvan, V., Podlogar, T., Sisask, M., Varnik, A., Wasserman, D., 2019. Bidirectional longitudinal associations between different types of bullying victimization, suicide ideation/attempts, and depression among a large sample of European adolescents. J. Child Psychol. Psychiatry 60, 209-215.

Caceda, R., Durand, D., Cortes, E., Prendes-Alvarez, S., Moskovciak, T., Harvey, P.D. Nemeroff, C.B., 2014. Impulsive choice and psychological pain in acutely suicidal depressed patients. Psychosom. Med. 76, 445-451.

Caceda, R., James, G.A., Stowe, Z.N., Delgado, P.L., Kordsmeier, N., Kilts, C.D., 2019. The neural correlates of low social integration as a risk factor for suicide. Eur. Arch. Psychiatry Clin. Neurosci.

Ding, Y., Lawrence, N., Olie, E., Cyprien, F., le Bars, E., Bonafe, A., Phillips, M.L., Courtet, P., Jollant, F., 2015. Prefrontal cortex markers of suicidal vulnerability in mood disorders: a model-based structural neuroimaging study with a translational perspective. Transl. Psychiatry 5, e516.

Ducasse, D., Holden, R.R., Boyer, L., Artero, S., Calati, R., Guillaume, S., Courtet, P., Olie, E., 2017. Psychological pain in suicidality: a meta-analysis. J. Clin. Psychiatry.

Eisenberger, N.I., Gable, S.L., Lieberman, M.D., 2007. Functional magnetic resonance imaging responses relate to differences in real-world social experience. Emotion 7, 745-754.

Eisenberger, N.I., Lieberman, M.D., Williams, K.D., 2003. Does rejection hurt? An FMRI study of social exclusion. Science 302, 290-292.

Foster, T., 2011. Adverse life events proximal to adult suicide: a synthesis of findings from psychological autopsy studies. Arch. Suicide Res. 15, 1-15.

Gratch, I., Choo, T.H., Galfalvy, H., Keilp, J.G., Itzhaky, L., Mann, J.J., Oquendo, M.A., Stanley, B., 2020. Detecting suicidal thoughts: The power of ecological momentary assessment. Depress. Anxiety.

Heikkinen, M., Aro, H., Lonnqvist, J., 1994. Recent life events, social support and suicide. Acta Psychiatr. Scand. Suppl. 377, 65-72.

Horesh, N., Rolnick, T., Iancu, I., Dannon, P., Lepkifker, E., Apter, A., Kotler, M., 1996. Coping styles and suicide risk. Acta Psychiatr. Scand. 93, 489-493.

Husky, M., Swendsen, J., Ionita, A., Jaussent, I., Genty, C., Courtet, P., 2017. Predictors of daily life suicidal ideation in adults recently discharged after a serious suicide attempt: a pilot study. Psychiatry Res. 256, 79-84.

Jollant, F., Lawrence, N.L., Olie, E., Guillaume, S., Courtet, P., 2011. The suicidal mind and brain: a review of neuropsychological and neuroimaging studies. World J. Biol. Psychiatry 12, 319-339.

Jollant, F., Lawrence, N.S., Olie, E., O’Daly, O., Malafosse, A., Courtet, P., Phillips, M.L., 2010. Decreased activation of lateral orbitofrontal cortex during risky choices under uncertainty is associated with disadvantageous decision-making and suicidal behavior. Neuroimage 51, 1275-1281.

Jollant, F., Near, J., Turecki, G., Richard-Devantoy, S., 2016. Spectroscopy markers of suicidal risk and mental pain in depressed patients. Prog. Neuropsychopharmacol. Biol. Psychiatry.

Klonsky, E.D., May, A.M., 2015. The three-step theory (3ST): A new theory of suicide rooted in the "ideation-to-action" framework. Int. J. Cogn. Therapy 8, 114-129.

Mackinnon, A., Ritchie, K., Mulligan, R., 1999. The measurement properties of a French language adaptation of the National Adult Reading Test. Int. J. Meth. Psychiatr. Res. 8, 27-38.

Meerwijk, E.L., Ford, J.M., Weiss, S.J., 2013. Brain regions associated with psychological pain: implications for a neural network and its relationship to physical pain. Brain Imaging Behav. 7, 1-14.

Oldfield, R.C., 1971. The assessment and analysis of handedness: the Edinburgh inventory. Neuropsychologia 9, 97-113.

Olie, E., Ding, Y., Le Bars, E., de Champfleur, N.M., Mura, T., Bonafe, A., Courtet, P., Jollant, F., 2015. Processing of decision-making and social threat in patients with history of suicidal attempt: a neuroimaging replication study. Psychiatry Res. 234 369-377.

Olie, E., Jollant, F., Deverdun, J., de Champfleur, N.M., Cyprien, F., Le Bars, E., Mura, T., Bonafe, A., Courtet, P., 2017. The experience of social exclusion in women with a history of suicidal acts: a neuroimaging study. Sci. Rep. 7, 89.

Oppenheimer, C.W., Silk, J.S., Lee, K.H., Dahl, R.E., Forbes, E., Ryan, N., Ladouceur, C. D., 2020. Suicidal ideation among anxious youth: a preliminary investigation of the role of neural processing of social rejection in interaction with real world negative social experiences. Child Psychiatry Hum. Dev. 51, 163-173.

Poldrack, R.A., 2007. Region of interest analysis for fMRI. Social Cogn. Affect. Neurosci. $2,67-70$.

Reisch, T., Seifritz, E., Esposito, F., Wiest, R., Valach, L., Michel, K., An fMRI study on mental pain and suicidal behavior. J. Affect. Disord. 126, 321-325.

Richard-Devantoy, S., Ding, Y., Lepage, M., Turecki, G., Jollant, F., 2016. Cognitive inhibition in depression and suicidal behavior: a neuroimaging study. Psychol. Med. 46, 933-944.

Sackeim, H.A., Haskett, R.F., Mulsant, B.H., Thase, M.E., Mann, J.J., Pettinati, H.M., Greenberg, R.M., Crowe, R.R., Cooper, T.B., Prudic, J., 2001. Continuation pharmacotherapy in the prevention of relapse following electroconvulsive therapy: a randomized controlled trial. JAMA 285, 1299-1307.

Scher, C.D., Forde, D.R., McQuaid, J.R., Stein, M.B., 2004. Prevalence and demographic correlates of childhood maltreatment in an adult community sample. Child Abuse Negl. 28, 167-180.

Schmaal, L., van Harmelen, A.L., Chatzi, V., Lippard, E.T.C., Toenders, Y.J., Averill, L.A., Mazure, C.M., Blumberg, H.P., 2020. Imaging suicidal thoughts and behaviors: a comprehensive review of 2 decades of neuroimaging studies. Mol. Psychiatry 25, 408-427.

Schneidman, E.S., 1996. The Suicidal Mind. Oxford University Press, New York.

Shiffman, S., Stone, A.A., Hufford, M.R., 2008. Ecological momentary assessment. Annual Rev. Clin. Psychol. 4, 1-32.

Troister, T., D’Agata, M.T., Holden, R.R., 2015. Suicide risk screening: comparing the beck depression inventory-II, Beck Hopelessness Scale, and Psychache Scale in undergraduates. Psychol. Assess. 27, 1500-1506.

van Heeringen, K., Van den Abbeele, D., Vervaet, M., Soenen, L., Audenaert, K., 2010. The functional neuroanatomy of mental pain in depression. Psychiatry Res. 181, 141-144.

Williams, K.D., Cheung, C.K., Choi, W., 2000. Cyberostracism: effects of being ignored over the Internet. J. Pers. Soc. Psychol. 79, 748-762. 